\title{
Malignant perivascular epithelioid cell tumor of the lung synchronous with a primary adenocarcinoma: one case report and review of the literature
}

\author{
Jikai Zhao', Haohua Teng ${ }^{1}$, Ruiying Zhao ${ }^{1}$, Wenjie Ding ${ }^{1}$, Keke Yu², Lei Zhu', Jie Zhang ${ }^{1}$ and Yuchen Han ${ }^{\text {1* }}$
}

\begin{abstract}
Background: Perivascular Epithelioid Cell Tumors (PEComa) is an extraordinarily rare mesenchymal neoplasm especially the malignant type originating from the lung. To date, only 8 cases of malignant or malignant potential pulmonary PEComa had been documented. Firm diagnostic criteria for malignant pulmonary PEComa need urgently to be established.

Case presentation: We report a challenging case of malignant pulmonary PEComa combined with a primary adenocarcinoma in a 54-year-old man. The PEComa-like tumor showed strong Melan-A and weak transcription factor E3 (TFE3) protein expression but no TFE3 gene rearrangement. The carcinoma-like nodule was recognized as a poorly differentiated primary lung adenocarcinoma.

Discussion and conclusions: Our case report was the first case of malignant pulmonary PEComa synchronous with a primary adenocarcinoma and studied the dilemma of diagnosing benign versus malignant criteria for this uncommon tumor.
\end{abstract}

Keywords: Perivascular epithelioid cell tumor, PEComa, Malignant, Clear cell tumor, Lung, Adenocarcinoma, Diagnostic criteria

\section{Background}

Perivascular Epithelioid Cell Tumor (PEComa) is a rare mesenchymal neoplasm which is thought to originate from perivascular epithelioid cells showing both melanocytic and myogenic differentiation [1]. Although this tumor was first described as a benign lung tumor in 1971 by Liebow and Castleman, it is extraordinary rare especially the malignant type originating from the lung [2].

Most PEComas are thought to follow a benign behavior. Clear cell tumor, angiomyolipoma, lymphangioleiomyomatosis, sugar tumor of the lung are all synonyms for this morphologically and immuno-phenotypically similar lesions [3]. Though malignant PEComa had been described and studied at numerous sites including soft

\footnotetext{
* Correspondence: hanyuchen1997@shchest.org

${ }^{1}$ Department of Pathology, Shanghai Chest Hospital, Shanghai Jiao Tong

University, No. 241 West Huaihai Road, Shanghai 200030, China

Full list of author information is available at the end of the article
}

tissue [4] and gynecologic Origin [5], retroperitoneum [6], gastrointestinal [7] and uterine [8,9], the diagnostic criteria and treatment strategy of malignant pulmonary PEComa have not been firmly established.

To date, only 8 cases of malignant or malignant potential pulmonary PEComa had been documented. We herein report a case of a 54-year-old man who synchronously presented with a well-demarcated mass in the right middle lobe and a small solid nodule in the left lower lobe. Since our case not only had a PEComa-like nodule and showed another solid nodule, the pressure on surgical management and frozen pathologic diagnosis is to judge whether the two tumors are homologous or heterogenous. The next challenge is to find and give preliminary evidence of histological features that determining its malignant behavior. Therefore, we described the difficulties of diagnosing malignant pulmonary PEComa in frozen and routine paraffin sections, and the

(c) The Author(s). 2019 Open Access This article is distributed under the terms of the Creative Commons Attribution 4.0 International License (http://creativecommons.org/licenses/by/4.0/), which permits unrestricted use, distribution, and reproduction in any medium, provided you give appropriate credit to the original author(s) and the source, provide a link to the Creative Commons license, and indicate if changes were made. The Creative Commons Public Domain Dedication waiver (http://creativecommons.org/publicdomain/zero/1.0/) applies to the data made available in this article, unless otherwise stated. 
predicament of surgical management we confronted. In this article, clinical and pathologic features were evaluated, immunohistochemical analysis and molecular alteration was studied.

\section{Case presentation}

A 54-year-old man was admitted to Shanghai Chest Hospital due to pulmonary shadow incidentally detected on routine chest roentgenograms. Computed tomography (CT) scan showed a large mass with partial pleural adhesion which seemed to originate from the mediastinal pleura rather than the right middle lobe (Fig. 1a-b). The tumor was well-circumscribed measuring about 4 $\mathrm{cm}$ and displayed heterogeneous enhancement (parenchyma of the tumor showed moderate contrast enhancement; $21 \mathrm{HU}$ (Hounsfield Unit) on pre-contrast image and $63 \mathrm{HU}$ on post-contrast image) (Fig. 1c). On the lung window image, one discrete $11 \mathrm{~mm}$ nodule was also noted in the left lower lobe, raising the possibility of lung-to-lung metastases (Fig. 1d). Right pleural localized enclosing effusion and mild enlargement of mediastinal lymph nodes were additional radiological findings.

Surgical procedures were tentatively scheduled for tumor dissection of the middle lobe and wedge-resection of the left lower lobe. Intraoperative frozen section of the larger mass was interpreted as indeterminate for malignancy in view of the atypical tumor cells growing in the interstitial surrounding blood vessels while the small solid nodule was diagnosed as a poorly differentiated adenocarcinoma (Fig. 2). Based on the above analysis and the patient approval, supplementary lobectomy of the right middle lobe and lymph node dissection were performed subsequently.

Gross specimen of the larger tumor showed a welldemarcated and non-encapsulated mass, with a grayish brown cut-surface and significant cystic lacunar structure (Fig. 3a). Microscopically, the tumor parenchyma was composed of epithelioid cells ranged in perivascular haemangiopericytoma-like patterns with clear or eosinophilic cytoplasm, with rich sinusoidal blood vessels (Fig. 3b). Trabecular-like and pellet-like growth pattern can be seen in some areas. Abundant clear intracellular glycogen displays positive Periodic Acid-Schiff staining with and without diastase digestion (Fig. 3c). Mass emergence of intra-nuclear pseudo-inclusions is an important morphological feature of this case. Neoplastic cells with obvious enlarged nucleoli and pathological mitosis were found. In addition, some dispersed bizarre hyperchromatic tumor giant cell (5/50 high-power fields) throughout the tumor is highly distinctive. The small solid nodular of the left lower lobe was confirmed as classic primary lung adenocarcinoma (Fig. 3d).

Immunohistochemistry showed strong positivity within tumor cells for Vimentin and Melan-A (Fig. 4a), weak but diffusely positive for TFE3 protein (Fig. 4b), while HMB45 was negative. The Ki-67 score was about $10 \%$. The neoplastic cells failed to stain with epithelial marker pan-cytokeratin and epithelial membrane antigen (EMA), myogenic marker caldesmon,
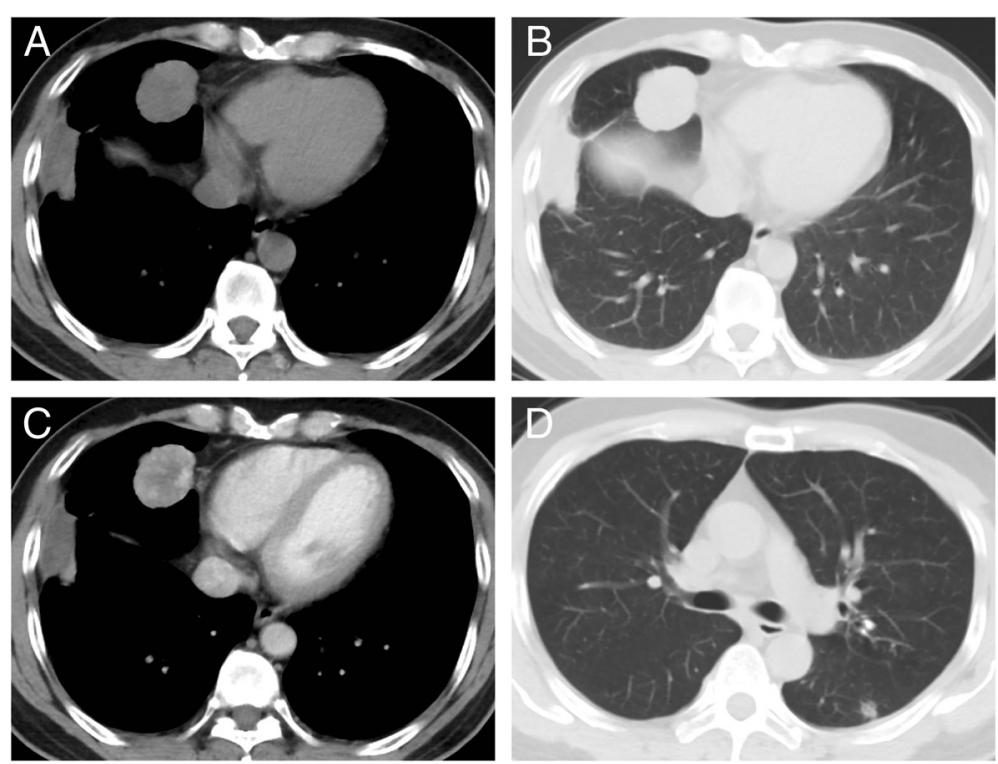

Fig. 1 Computed tomography (CT) scan of the lung tumor. $\mathbf{a}, \mathbf{b}$ A larger lesion was located in the right middle lobe with smooth boundary measured $4 \mathrm{~cm} \times 3.5 \mathrm{~cm} \times 2 \mathrm{~cm}$, accompanied by heterogeneous enhancement (c). $\mathbf{d}$ Another small nodule about $11 \mathrm{~mm}$ was located in the left lower lobe with lobulated shape and spicules of margin 

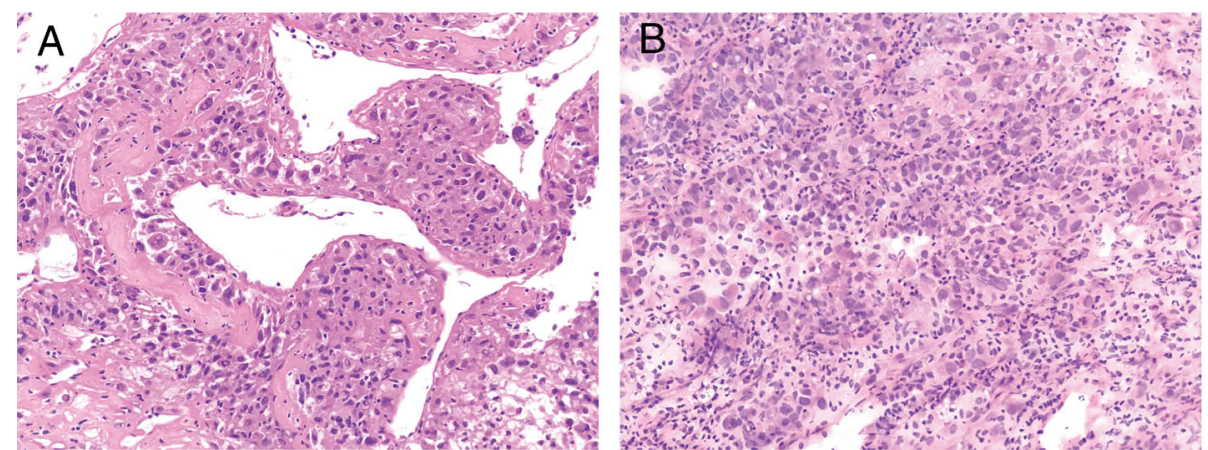

Fig. 2 Intraoperative frozen section. a The middle lobe tumor composed of atypical epithelioid neoplasm cells organized in a angiopericytomalike pattern, growing in the interstitial with abundant clear or granular cytoplasm. $\mathbf{b}$ The small solid nodule suggested a poor differentiated adenocarcinoma (original magnification $\times 200$ )

myogenin and $\alpha$-smooth muscle actin ( $\alpha$-SMA), and additional antibodies including neuroendocrine mar kers.

TFE3 gene rearrangement was not identified by fluorescence in-situ hybridization and reverse transcription polymerase chain reaction (RT-PCR). The results of targeted molecular gene alteration including epidermal growth factor receptor (EGFR), anaplastic lymphoma kinase (ALK), ROS proto-oncogene 1(ROS1), kirsten rat sarcoma viral oncogene (K-ras) of these two tumors were all negative.

The patient underwent three courses of chemotherapy of combined paclitaxel $(300 \mathrm{mg})$ and carboplatin (600 $\mathrm{mg}$ ) after surgery. A follow up fluorine-18-fluorode oxyglucose positron emission tomography/computed tomography $\left({ }^{18} \mathrm{~F}\right.$-FDG $\left.\mathrm{PET} / \mathrm{CT}\right)$ obtained 12 months after chemotherapy showed no metastatic lesions elsewhere. At present, the disease is stable and the patient is followed-up regularly.

\section{Discussion and conclusions}

Conventional PEComas frequently harbor tuberous sclerosis complex (TSC) gene mutation [10]. A distinct subset of PEComa carrying transcription factor E3 (TFE3) gene rearrangements were identified arising in the uterine corpus, vagina, and pelvic and pulmonary tumor [11]. They typically are strongly positive for TFE3 and HMB45, with purely clear cell epithelioid cells and
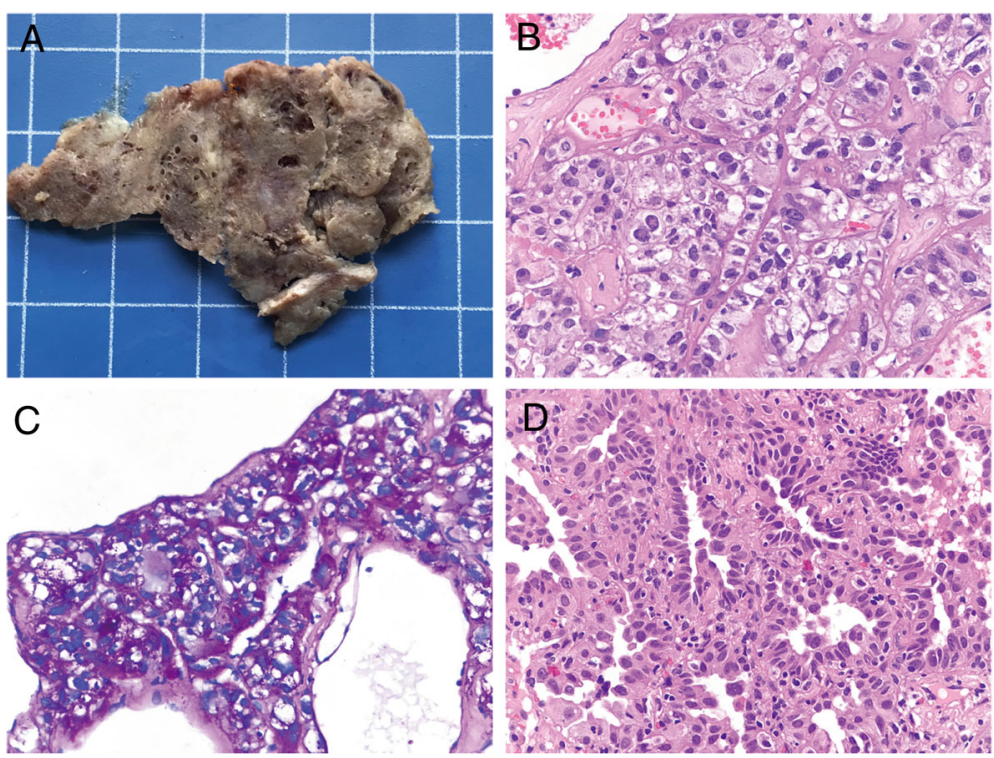

Fig. 3 Gross and microscopic examination of the resected specimens. a Gross examination after fixation of the middle lobe mass had a grayish brown cut-surface and significant cystic lacunar structure. b Tumor parenchyma displayed perivascular haemangiopericytoma-like and solid sheets structure around sinusoidal blood vessels. c Periodic Acid-Schiff staining indicated abundant clear intracellular glycogen. $\mathbf{d}$ The small nodule of the left lower lobe was invasive lung adenocarcinoma presenting as acinar and solid subtype. $\mathbf{b}, \mathbf{c}$ and $\mathbf{d}$, original magnification $\times 400$ ) 


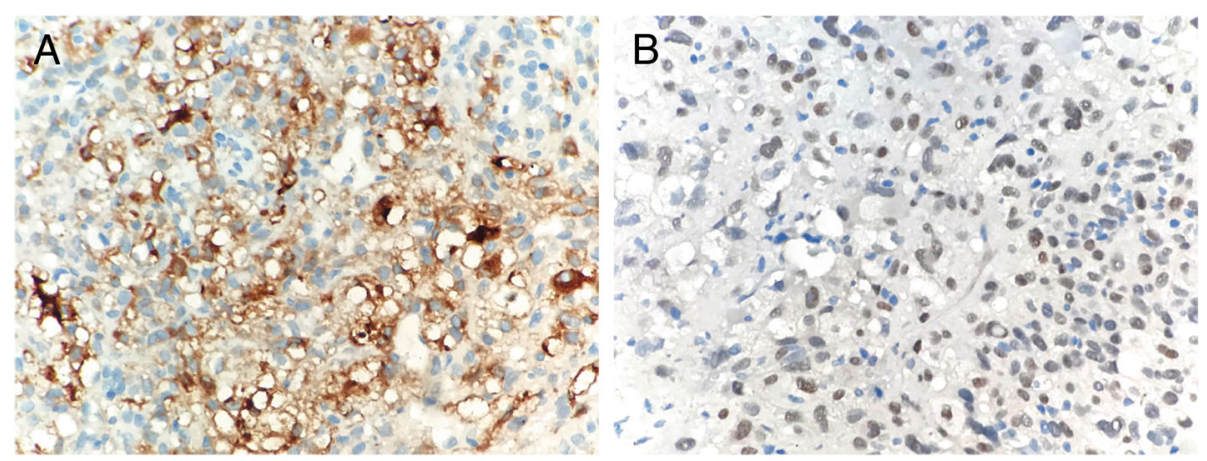

Fig. 4 Immunohistochemistry staining of the malignant perivascular epithelioid cell tumor. a Tumor cells showed strong positivity for Melan-A, weak but diffuse and consistently positivity nuclear staining for TFE3 $\mathbf{b}$

an alveolar architecture [12-14]. But it is still uncertain what the role of TFE3 is in malignant pulmonary PE Coma. Recognition of this genetic abnormality may have critical therapeutic implications for aggressive tumor in future.

Including six cases in the English literature and two cases documented in the Chinese literature, a total of 8 aggressive or malignant PEComas of the lung have been reported [15-20]. These documents illustrated the invasive clinical behavior of the tumor from a series of angles, including tumor size, infiltrative growth pattern, nuclear grade, necrosis, and mitotic activity. According to most literatures, malignant PEComa of the lung also appeared radiologically as a solitary, well-defined nodule like benign clear cell sugar tumor, without cystic changes and calcification. Only one recently reported case showed spindle cell morphology and significant calcification.

Histopathologically, PEC tumor should be differentiated from primary clear cell pulmonary carcinoma, a variant of adenocarcinoma according to 2015 World Health Organization (WHO) classification of tumors of the lung, carcinoid, metastatic renal clear cell carcinoma, paraganglioma, primary intrapulmonary meningothelial neoplasm and malignant melanoma.

As with more and more recognized cases at numerous sites, diagnostic criteria for malignant PEComa continue to evolve. Firm diagnostic criteria for malignant pulmonary PEComa also need to be urgently established. Therefore, we put forward some suggestions for reference in diagnosis of malignant lung PEComa according to our experience and retrospective literature analysis. The primary diagnostic criteria include: prominent coagulative tumor necrosis; infiltrates and invade adjacent pleura or viscera; distant metastasis of homology; pathological mitotic figure $\geq 1 / 50 \mathrm{HP}$. Secondary diagnostic criteria are as follows: tumor size $\geq 3 \mathrm{~cm}$; spotty necrosis; high mitotic index $\geq 5 \%$; multinucleated tumor giant cell $\geq 5$ / 50HP; marked hyper-cellularity; nuclear atypia and pleomorphism; numerous intranuclear pseudoinclusion.
The criteria for the diagnosis of malignant lung PEComa that we recommend are that the tumor meets 1-2 major diagnostic criteria and/or one more secondary diagnostic criteria. If the tumor satisfies only 2 or more secondary diagnostic criteria, we suggest the diagnosis of lung PEComa with malignant potential.

Scope of surgical resection and lymph node dissection and subsequent medical treatment of malignant PEComa is another challenge. Complete surgical resection is probably the most effective treatment at present. As for the need for combined chemotherapy, it should be considered the degree of histologic differentiation and whether the tumor is associated with a primary malignant tumor. In our case, the middle lobe lesion was successfully removed from normal surrounding parenchyma and a wedge resection of left lower lobe was carried out. The right middle lobectomy and lymph node dissection were finally performed. Three courses of toxic chemotherapy were performed targeting for lung adenocarcinoma after operation, and we speculated that the prognosis of malignant PEComa may benefit from the strategy. Postoperatively, follow up ${ }^{18}$ F-FDG PET CT showed no evidence of residual tumor or metastatic lesions elsewhere.

Pulmonary malignant PEComa associated with a primary poorly differentiated adenocarcinoma has not been described previously. TFE3 gene mutation was not identified in this case. Due to this tumor's uncommon occurrence, the diagnostic criteria of this entity are not widely known and may lead to misdiagnosis. Therefore, its malignant characteristics may be multifaceted and need to be addressed from different angles and more examples.

\footnotetext{
Abbreviations

${ }^{18}$ F-FDG PET/CT: Fluorine-18-fluorodeoxyglucose positron emission tomography/computed tomography; ALK: Anaplastic lymphoma kinase; EGFR: Epidermal growth factor receptor; EMA: Epithelial membrane antigen; K-ras: Kirsten rat sarcoma viral oncogene; PEComa: Perivascular epithelioid cell tumor; ROS1: ROS proto-oncogene 1; TFE3: Transcription factor E3; TSC: Tuberous sclerosis complex; WHO: World Health Organization; a-SMA: asmooth muscle actin
} 


\section{Acknowledgments}

Not applicable.

\section{Funding}

This work was funded by Intelligent Medical Research Project of Shanghai Municipal Health Commission (2018ZHYL0213 ).

\section{Availability of data and materials}

The datasets used during the current study are available from the corresponding author on reasonable request.

\section{Authors' contributions}

YCH and JKZ designed the study. JKZ and LZ performed the experiments and $H H T$ interpreted the pathologic and imaging data. RYZ and HHT completed the molecular analysis. WJD and KKY guaranteed the technical support. JZ provided conceptual advice and participated in the revision of the article structure, as well as the discussion of the diagnosis. JKZ and LZ wrote the manuscript. YCH supervised the entired project. All authors and contributors read and approved the final manuscript.

\section{Ethics approval and consent to participate}

The Ethics Committee of Shanghai Chest Hospital of Shanghai Jiao Tong University approved this study. The patient agreed to participate in the study with all relevant data. And written informed consent was obtained from the patient.

\section{Consent for publication}

Written informed consent for publication of the clinical details and clinical images was obtained from the patient.

\section{Competing interests}

All authors declare that they have no competing interests.

\section{Publisher's Note}

Springer Nature remains neutral with regard to jurisdictional claims in published maps and institutional affiliations.

\section{Author details}

'Department of Pathology, Shanghai Chest Hospital, Shanghai Jiao Tong University, No. 241 West Huaihai Road, Shanghai 200030, China. ${ }^{2}$ Department of Bio-Bank, Shanghai Chest Hospital, Shanghai Jiao Tong University, Shanghai, China.

Received: 15 May 2018 Accepted: 19 February 2019

Published online: 15 March 2019

\section{References}

1. Folpe AL, Kwiatkowski DJ. Perivascular epithelioid cell neoplasms: pathology and pathogenesis. Hum Pathol. 2010;41(1):1-15.

2. Liebow AA, Castleman B. Benign clear cell ("sugar") tumors of the lung. Yale J Biol Med. 1971;43:213-22.

3. Fletcher CDM, Unni KK, Mertens F, et al. International academy of pathology: pathology and genetics of Tumours of soft tissue and bone. Lyon. France: IARC Press; 2002. p. p230-3.

4. Harris GC, McCulloch TA, Perks G, Fisher C. Malignant perivascular epithelioid cell tumour ("PEComa") of soft tissue: a unique case. Am J Surg Pathol. 2004;28(12):1655-8.

5. Folpe AL, Mentzel T, Lehr HA, et al. Perivascular epithelioid cell neoplasms of soft tissue and gynecologic origin: a clinicopathologic study of 26 cases and review of the literature. Am J Surg Pathol. 2005;29(12):1558-75.

6. Lau SK, Marchevsky AM, McKenna RJ Jr, et al. Malignant monotypic epithelioid angiomyolipoma of the retroperitoneum. Int J Surg Pathol. 2003; 11:223-8.

7. Doyle LA, Hornick JL, Fletcher CD. PEComa of the gastrointestinal tract: clinicopathologic study of 35 cases with evaluation of prognostic parameters. Am J Surg Pathol. 2013;37(12):1769-82.

8. Greene LA, Mount SL, Schned AR, et al. Recurrent perivascular epithelioid cell tumor of the uterus (PEComa): an immunohistochemical study and review of the literature [J]. Gynecol Oncol. 2003;90(3):677-81.

9. Ciarallo A, Makis W, Hickeson M, et al. Malignant perivascular epithelioid cell tumor (PEComa) of the uterus: serial imaging with F-18 FDG PET/CT for surveillance of recurrence and evaluation of response to therapy. Clin Nucl Med. 2011;36(4):e16.

10. Agaram NP, Sung YS, Zhang $L$, et al. Dichotomy of genetic abnormalities in pecomas with therapeutic implications. Am J Surg Pathol. 2015;39(6):813.

11. Argani $P$, Aulmann $S$, Illei $P B$, et al. A distinctive subset of PEComas harbors TFE3 gene fusions. Am J Surg Pathol. 2010;34:1395-406.

12. Schoolmeester JK, Dao LN, Sukov WR, et al. TFE3 translocation-associated perivascular epithelioid cell neoplasm (PEComa) of the gynecologic tract: morphology, immunophenotype, differential diagnosis. Am J Surg Pathol. 2014;38(2):176-88.

13. Malinowska I, Kwiatkowski DJ, Weiss $S$, et al. Perivascular epithelioid cell tumors (PEComas) harboring TFE3 gene rearrangements lack the TSC2 alterations characteristic of conventional PEComas: further evidence for a biological distinction. Am J Surg Pathol. 2012;36(5):783-4.

14. Shen Q, Rao Q, Xia QY, et al. Perivascular epithelioid cell tumor (PEComa) with TFE3 gene rearrangement: Clinicopathological, immunohistochemical, and molecular features. Virchows Archiv. 2014:465(5):607-13.

15. Sale GE, Kulander BG. "Benign" clear-cell tumor (sugar tumor) of the lung with hepatic metastases ten years after resection of pulmonary primary tumor. Arch Pathol Lab Med. 1988:112:1177-8.

16. Parfitt JR, Keith JL, Megyesi JF, et al. Metastatic PEComa to the brain [J]. Acta Neuropathol. 2006:112(3):349-51.

17. Ye $\mathrm{T}$, Chen $\mathrm{H}, \mathrm{Hu} \mathrm{H}$, et al. Malignant clear cell sugar tumor of the lung: patient case report. J Clin Oncol. 2010;28:e626-8.

18. Lim HJ, Lee HY, Han J, et al. Uncommon of the uncommon: malignant perivascular epithelioid cell tumor of the lung. Korean J Radiol. 2013;14:692-6.

19. Liang W, Xu S, Chen F. Malignant perivascular epithelioid cell neoplasm of the mediastinum and the lung: one case report. Medicine. 2015: 94(22):e904.

20. Song Y, Chen F, Zhang C, et al. Spindle cell subtype of pulmonary clear cell tumor with prominent calcification and malignant potential. Thoracic Cancer. 2017;8(5):530-4.

\section{Ready to submit your research? Choose BMC and benefit from:}

- fast, convenient online submission

- thorough peer review by experienced researchers in your field

- rapid publication on acceptance

- support for research data, including large and complex data types

- gold Open Access which fosters wider collaboration and increased citations

- maximum visibility for your research: over $100 \mathrm{M}$ website views per year

At $\mathrm{BMC}$, research is always in progress.

Learn more biomedcentral.com/submissions 